\title{
Goodbye Justice, Hello HAPPINESS: WELCOMING Positive Psychology to THE LAW
}

\author{
MIRKo Bagaric ${ }^{*}$ AND JAMES McConVILL“*
}

\begin{abstract}
[Legal regulation is the most coercive and effective behaviour modifying tool in our community. As a general rule, law relates to the areas of human activity which are viewed as important to the human condition. It follows that the content of the law; that is, legal rules and principles, are central to human happiness. This is not controversial. Laws are purposeful. This is a point that has always been recognised implicitly or expressly by law-makers, philosophers, lawyers and the community at large. This is reflected in the fact the people evaluate and critique legal standards. There are supposedly 'good' laws, 'bad' laws and many in the middle. While we all agree that law is purposeful, there has been intense debate over the centuries regarding the appropriate ends of law. Most forcefully it has been argued that the ultimate ends of the law, the benchmark against legal systems and laws should be evaluated, is the notion of justice. Laws are also often benchmarked on the basis of economic criteria. This paper contends that such standards are flawed benchmarks for evaluating the legal system. In the normal scheme of things, law should be evaluated by one criterion: its capacity to promote human well-being (or happiness). New developments in positive psychology (a discipline that has to date been ignored by law makers and legal commentators) conclusively establish that not only can the level of happiness be scientifically measured, but that we are very similar in terms of the activities that are conducive or inimical to our well-being. We have the same basic desires and needs and it is possible to develop a road map to happiness. We can now tell with a large degree of confidence whether a given activity is
\end{abstract}

\footnotetext{
* Professor of Law and Head of Deakin Law School.

${ }^{* * *}$ Lecturer, School of Law, Deakin University.
} 
likely to diminish or promote happiness. The current state of research makes it possible for us to predict with a high degree of confidence the likely effect that many laws have on human flourishing. Further research in this area will facilitate the increasing accuracy of such predictions. Happiness is a more relevant and important benchmark than justice because, despite the thousands of years that have been spent examining the notion of justice, its meaning remains vague and indeterminate and hence provides little guidance on important issues. More importantly, justice is less important than happiness. Who needs justice if we are all happy?]

\section{INTRODUCTION}

\section{A Law Relates to Important Human Activities}

Legal regulation is the most coercive and effective behaviour modifying tool in society. It has the capacity to significantly shape and guide not only our judgments and mind set but, even more importantly, our behaviour and activities. As a general rule, law relates to the areas of human activity which are viewed as important to the human condition. Thus, all societies have laws governing the scope and content of interests such the right to life, bodily integrity, the right to property and so on.

It follows that the content of the law, that is legal rules and principles, has a significant impact on human flourishing. This is not controversial. Laws are purposeful. This is a point that has always been recognised implicitly or expressly by lawmakers, philosophers, lawyers and the community at large. This is reflected in the fact that people evaluate and critique legal standards. There are supposedly 'good' laws, 'bad' laws and many in the middle. Even laws which on the surface appear to be value neutral, often incorporate a value judgment. The rule that motorists in the United States must drive on the right hand side of the road, does not stem from the belief that driving on the right hand side of the road is for some reason intrinsically preferable to the left hand side of the road. On the surface this law is simply designed to co-ordinate human affairs. However, even laws of this nature are motivated by a value judgment, in this case that we should try to reduce the incidents of head-on collisions and the consequent risk to life and property. The same rule in a community where people had difficulty distinguishing the left and right side of their body would be heavily criticised as being an inadequate law.

While there is widespread consensus that law is a purposeful and important social institution, there has been intense debate over the centuries regarding the appropriate ends of law. Most forcefully it has been argued that the ultimate ends of the law, and the benchmark against which legal systems and laws should be evaluated, is the notion of justice, which to many theorists is the application of important moral norms to the legal domain. Laws are also often benchmarked on the basis of economic criteria. Thus, commentators regularly critique laws on the basis of their 
impact on the economic prosperity of the community or certain groups or individuals within the community.

\section{B Happiness does not have a recognised role in develop- ing the law}

This paper contends that such standards are flawed benchmarks for evaluating laws in particular and legal systems in general. In the normal scheme of things, law should be evaluated by one criterion: its capacity to promote human well-being (or happiness - these terms are used interchangeably by happiness scientists, as they are in this paper). In a very crude manner this type of evaluation already occurs. Happiness or well-being are often not the precise words employed, however, when people state, as they often do, that a law is bad because it will adversely affect some members of the community, the connotation normally is that it is detrimental to happiness.

The capacity to persuasively critique laws on the basis of happiness has been severely curtailed over the ages for one reason: happiness has always been viewed as being too vague and subjective to provide pointed answers regarding the things that are conducive to human flourishing. While it is obvious that people need food, shelter, health care, education and a sense of personal security, beyond this the general view has been that the conditions that promote happiness vary from person to person. This is supported by the almost infinite number of activities and projects that people choose to pursue. The richness and diversity of the human species seems to militate against the idea that there is even approximate convergence concerning the things that are conducive to happiness. Hence, law makers have ignored happiness as been an important and guiding determinant in making laws - certainly, it has not been at the forefront of their consciousness or featured prominently in their endeavours to explain or justify laws. While there is a cursory level of understanding of happiness as a concept, it has not been regarded as a virtue that is capable of forming the foundation for a coherent system of law.

\section{Happiness is objective - people are all very similar}

In the past few decades, however, there has been an explosion in the amount of studies conducted into human happiness and well-being. Most recently, in January 2005 Time Magazine devoted a whole edition to exploring "The New Science of Happiness". While noting the diversity in the range of activities through which people choose to express themselves, the studies show that at the base we are not that different after all. At the core, humans are 'wired' pretty much the same. While some people prefer singing in a choir as opposed to boxing in a ring, and others prefer repairing motor vehicles to writing poetry, we should not allow these superficial differences to divert us from the fact that we have the same basal needs and our well-being is promoted by the same type of things.

We can now confidently identify the things that make us happy. These include a high degree of liberty, so that we are free to pursue our individual goals, a sense of 
participation and control in the activities we engage in, close personal relationships, good health and the pursuit of challenging projects and activities. We also know some things that do not make us happy. One of these, generally speaking, is money; another is engaging in passive forms of 'activity' such as watching television.

New developments in positive psychology (a discipline that has to date been largely ignored by law makers and legal commentators) and brain research conclusively show that not only are we very similar in terms of the activities that are conducive or inimical to our well-being but that happiness levels can be scientifically measured. We have the same basic wants and needs and it is possible to develop a road map to happiness.

In relation to many laws, the current state of research makes it possible for us to predict with a high degree of confidence the likely effect that such laws will have on human flourishing. Pointed future research in this area will facilitate the accuracy of such predictions. The importance of these findings cannot be overstated. They provide those responsible for social engineering, ie law makers, with a blueprint for constructing the sort of community in which people will flourish.

There will no doubt be sceptics who will remain slaves to unsubstantiated economic and social objectives, such as the pursuit of economic rationalism or an esoteric form of justice (as most versions of justice tend to be), despite the emerging evidence of what it is that really matters to people. To this end, it is important to point out that the scientific methodology used to ascertain the results relating to human well-being is the same as that used to obtain medical and biological information about people. Thus, a denial that, for example, money does not cause happiness is just as specious as the claim that excess alcohol does not cause sclerosis of the liver. In this respect it is particularly important to note that one or two counter-examples do not disprove a general point. The claim that some people are happier after they make lots of money no more disproves the point that money does not make people happy, than the fact that one has a relative who drank two bottles of wine a day and lived until he or she was 95 years of age disproves the link between alcohol and liver damage.

Happiness is a more relevant and important benchmark than justice because, despite the thousands of years that have been spent examining the notion of justice, its meaning remains vague and indeterminate and hence provides little guidance on important issues. Moreover, justice is less important than happiness. Who needs justice if we are all happy?

\section{Overview of paper}

In the next section of this paper we discuss the nature of happiness and its importance to human beings. In section three we discuss the results of happiness studies and spell out the activities which promote happiness. In section four, we briefly discuss some of the ramifications that these results have for the content of the law. 
This is followed, in section five, by a discussion of the relevance of moral norms to our proposed system of legal development.

\section{Why Happiness MatTers Most}

\section{A What is happiness?}

In Nicomachean Ethics, Aristotle wrote that happiness is 'the whole aim and end of human existence'. According to Aristotle:

Happiness is an activity; and activity plainly comes into being and is not present at the start like a piece of property . . . happiness is good activity, not amusement ... for, in a word, everything that we choose we choose for the sake of something else--except happiness, which is an end . . f for happiness does not lie in such occupations, but, as we have said before, in virtuous activities . . . Happiness extends, then, just so far as contemplation does, and those to whom contemplation more fully belongs are more truly happy, not as a mere concomitant but in virtue of the contemplation; for this is in itself precious. Happiness, therefore, must be some form of contemplation.

For the ancient Creeks and Romans, to be happy was to live serenely, above the world's swings of passion and material fortune. ${ }^{1}$ For Epicurus, happiness derived from life's sustainable pleasures, such as tranquil peace of the mind. ${ }^{2}$

Numerous other definitions have been put forward over the centuries, however, in essence happiness is

a pervasive sense that life is good. Well-being outlasts yesterday's moment of elation, today's buoyant mood, and tomorrow's hard time; it is an ongoing perception that this time of one's life, or even life as a whole, is fulfilling, meaningful, and pleasant. ${ }^{3}$

As we shall see in section 4.3 below, happiness can be further broken into different types of sentiments, namely gratifications and pleasures. Moreover, we shall also see that not only can happiness be defined, but it can be scientifically measured by means of devices that detect brain activity.

\footnotetext{
${ }^{1}$ DAVID MYERS, THE PURSUIT OF HAPPINESS 16 (1992)

${ }^{2} I d$. at 16.

${ }^{3} I d$. at 24 .
} 


\section{B Why is Happiness Important (And Thus Worthy of Being Promoted)?}

There are two levels where the issue of why happiness is important becomes relevant. The first is at the level of personal motivation and desire, it being suggested that happiness is the ultimate aim of mankind. However, what proof is there of this?

\section{$1 \quad$ As an Empirical Fact People Desire Happiness Most}

Accordingly to Jeremy Bentham, this premise that people desire happiness most is incapable of proof. For him, it was the ultimate principle, which could not be proved by another principle: 'is it susceptible of any direct proof? It should seem not: for that which is used to prove every thing else, cannot itself be proved: a chain of proofs must have their commencement somewhere'. ${ }^{4}$

Nevertheless, something more beyond the assertion of the premise can be said. The evidence in favour of this premise is the incongruity in the assertion that 'I don't want to be happy'. Such a statement normally prompts puzzlement and requires an explanation - far more so than the denial of any other desire. It normally leads to a suspicion that the agent is either confused, irrational or disingenuous. The same degree of suspicion does not attach to a denial of other desires, which are often regarded as being highly pervasive, such as the desire to be wealthy, wise, famous, beautiful, or even healthy. This observation supports the view that in the end the thing which we desire most is to be happy.

In addition to this, apart from the intrinsic benefit stemming from happiness, there are derivative benefits flowing from this. The benefits of happiness go beyond the psychic sensation. Happy people report less aches and pains and are more energetic, decisive and flexible. They also tolerate more frustration and are less likely to be abusive. They are more forgiving and are good to have around because they are more willing to help those in need. ${ }^{6}$ 'The feel-good, do-good phenomenon' is genuine. Thus, 'human happiness is both an end - better to live fulfilled, with joy - and a means to a better caring and healthy society'. ${ }^{7}$

\section{$2 \quad$ At the Normative Level People Are Not Required to Shun Personal Happiness}

The second level at which the issue of why happiness is important is at the normative level. A detailed examination of moral theory is beyond the scope of this paper.

\footnotetext{
${ }^{4}$ Jeremy Bentham, An Introduction to the Principles of Morals and Legislation, in WORKS 2 (TJ Bowring ed.,1843)

${ }^{5}$ As an empirical fact, many people seem to pursue such interests even at the expense of happiness. Mill explained this on the basis of the doctrine of 'constant association'. There is such a close connection between these pursuits as a means to happiness, that many agents in fact confuse them for the ultimate goal.

${ }^{6}$ See MYERS, above n 1, 20-21.

${ }^{7}$ Id.
} 
Nevertheless, it is necessary to make some comment on how the arguments we are making in this paper sit with the dictates of moral discourse. This is particularly so given the fact that because one wants to do something, does not entail that they should necessarily follow that course of action - `an ought cannot be derived from an is'. 8

To this end, we note that in our view there is a total convergence between is and ought in this context. One of us has previously argued that the soundest moral theory is utilitarianism, and advanced a logical proof in favour of this argument. ${ }^{9}$ If this is right, morality and human nature both urge us to act in a manner which will maximise happiness and hence the approach we suggest to legal development is correct at both the sociological and normative levels. We recognise, of course, that utilitarianism is no longer the 'flavour of the month' so far as moral discourse is concerned - it has not been for a long time.

The leading contemporary moral theories are non-consequentialist which are framed in the language of rights. Following the Second World War, there has been an immense increase in 'rights talk', ${ }^{10}$ both in number of supposed rights and in total volume. Rights doctrine has progressed a long way since its original aim of providing 'a legitimization of ... claims against tyrannical or exploiting regimes'.11 As Tom Campbell points out:

The human rights movement is based on the need for a counter-ideology to combat the abuses and misuses of political authority by those who invoke, as a justification for their activities, the need to subordinate the particular interests of individuals to the general good. ${ }^{12}$

There is now, more than ever, a strong tendency to advance moral claims and arguments in terms of rights. ${ }^{13}$ Assertion of rights has become the customary means

\footnotetext{
${ }^{8}$ This has been used as an argument against a naturalistic view of morality. However, see C R Pigden, Naturalism, in A COMPANION TO ETHICS 421-426 (Peter Singer ed., 1991) where he points out that this phenomenon simply reflects the conservative nature of logic - you cannot get out of it, what you do not put in.

${ }^{9}$ Mirko Bagaric, A Utilitarian Argument: Laying the Foundation for a Coherent System of Law, 10 OTAGO L. REV. 163 (2002).

${ }^{10}$ See Tom Campbell, The Legal Theory of Ethical Positivism 161-88 (1996) who discusses the near universal trend towards Bills of Rights and constitutional rights as a focus for political choice. By 'rights talk' we also included the abundance of declarations, charters, bills, and the like, such as the Universal Declaration of Human Rights, 1948; the International Covenant of Economic, Social and Cultural Rights, 1966; and the European Convention for the Protection of Human Rights and Fundamental Freedoms, 1966, that seek to spell out certain rights. Granted, numerous examples of rights-based language existed prior to the Second World War, such as the Declaration of Independence of the United States, 1776 and the Declaration of the Rights of Man and Citizens, 1789; however, it is only in relatively modern times that such documents have gained widespread appeal, recognition and force.

${ }^{11}$ Simon Benn, Human Rights - For Whom and For What? , in HUMAN RigHTS 59-61 ( E Kamenka \& A E Tay eds.,1978).

${ }^{12}$ Tom Campbell, Realizing Human Rights, in HuMAN RIGHTS: FrOM RHETORIC TO REALITY 1-13 (Tom Campbell et.al., ed., 1996).

${ }^{13}$ Almost to the point where it is not unthinkable to propose that the "escalation of rights rhetoric is out of control': see L W Sumner, THE MORAL FOUNDATION OF RIGHTS 1 (1987).
} 
to express our moral sentiments. As Sumner notes: 'there is virtually no area of public controversy in which rights are not to be found on at least one side of the question - and generally on both'. ${ }^{14}$ The domination of rights talk is such that it is accurate to state that human rights have at least temporarily replaced maximising utility as the leading philosophical inspiration for political and social reform. ${ }^{15}$

Despite the prominence of rights based theories, for present purposes it is important to note even in this context there is no defensible reason to resist the pursuit of personal happiness. No tenable moral theories urge people to forego the pursuit of personal happiness. This is especially the case with rights-based theories which are individualising in nature and promote the interests of the individual as being the paramount moral commodity. So long as individual interests equate with individual happiness, it is obvious our proposal sits comfortably even within a rights-based ethic. Further, if a moral theory required of us to desist from pursuing happiness, as a matter of psychological reality, it would become self-defeating. ${ }^{16}$ If the ultimate principle guiding our conduct fails to reflect our ultimate desire, it would become redundant very quickly.

\section{What Makes People Happy?}

So what makes people happy?

The starting point is one of the most interesting and important books of the late 20th century, The Pursuit of Happiness, by David Myers in which he draws together the results of hundreds of surveys on human well being in search of common variables that make people happy.

\section{A Methodology \\ $1 \quad$ Representative sampling}

The methodology used in the surveys reported in David Myers' book is the same as that adopted in relation to most scientific experiments. A hypothesis is developed and is then tested through experimentation involving a representative and statistically significant number of respondents. ${ }^{17}$ This method is far more accurate than haphazard sampling. ${ }^{18}$

To ascertain people's sense of well-being, people were asked to report their feelings of happiness or unhappiness along with their thoughts of how satisfying their lives

\footnotetext{
${ }^{14} I d$.

${ }^{15}$ H L A HART, ESSAYS IN JURISPRUDENCE AND PHILOSOPHY 196-7 (1983).

${ }^{16}$ See Bagaric, supra note 9.

${ }^{17}$ In this regard he noted that 1,500 randomly sampled people provides an accurate snapshot of 100 million people.

${ }^{18}$ See MYERS, supra note 1 , at 17.
} 
were $^{19}$ - the results were that people who feel happy also think their lives are satisfying. Sometimes this was probed according to a single measure, on other occasions researchers probed with multi-item measures. One method which was used to gauge the impact of suspected variables on happiness was to give two equivalent groups an experience that differed only in that factor. Thus, in order to determine if people are happier by accumulating wealth, people were randomly assigned to either experience or not experience this factor. ${ }^{20}$

In terms of how happiness is tested, happiness is obviously a state of mind and the ultimate and only judge is the individual. If you feel happy, you are happy. Despite this, there is obviously the problem that people may be disingenuous in their selfreports of happiness. And indeed, there is a distinct tendency for people to overreport good feelings. ${ }^{21}$ However, this does not undermine the accuracy of the studies. This is because happiness is a relative concept:

To discover who is happiest, and why, we need only assume that those who say they are "very happy" or "completely satisfied" do experience greater well-being than those who say they are unhappy or dissatisfied. ${ }^{22}$

\section{$2 \quad$ Eliminating distorting variables}

Another possible bias in the results is the momentary moods of people. This does not, however, impugn the validity of the results. First, people tend to attribute judgements of well-being to their overall situation as opposed to transient feelings. It is noteworthy that the happiness level of people is remarkably consistent over their lifetime. ${ }^{23}$ Second, people experience both good and bad transient mood altering experiences. Thus, to the extent these experiences impact on subjective feelings of well-being they will in a properly selected sample of people cancel each other out in terms of the overall result. Further, when comparing across samples each sample will have approximately equal numbers of people in good and bad moods at the time of the respective studies.

It follows that the same empirical techniques that have been used to test scientific truths apply here. The findings, therefore, are as equally valid as findings concerning other aspects of the human condition - including medical and biological findings.

As noted below, apart from the work of Myers, there has been an explosion in empirical studies as to what makes people happy in recent years, with 'happiness' increasingly becoming a scientific rather than theoretical concept. The overriding pursuit of happiness is now a psychological truism rather than a 'heady' aspirational

\footnotetext{
${ }^{19} \mathrm{Id}$. at 24 .

${ }^{20}$ Id. at $18-19$.

${ }^{21} I d$ at 27.

${ }^{22} \mathrm{Id}$. at 28.

${ }^{23} \mathrm{See}$ below.
} 
objective. There is now a dedicated international journal, the 'Journal of Happiness Studies' which is devoted to articles based on empirical studies of what makes people happy (or indeed unhappy), and over the last few years there has been a number of important works looking at what makes people happy, and in particular looking at whether there is a positive or negative correlation between happiness and wealth creation. The study of happiness is becoming a discipline in itself, and one with great practical relevance for the discipline of law. We now look at the results from the research to date.

\section{B The Results - the things that make people happy}

\section{$1 \quad$ Participation and freedom}

Myers found that people function best in circumstances of democracy and personal freedom. Involvement and a sense of contribution and control over the activities that impact on one's life are key ingredients to a sense of well-being. The connection between participation, control and happiness manifests in many sorts of domains: 'study after study finds that when workers have more control - when they can help define their own goals and hours and when they can participate in decision making - their job satisfaction rises'. ${ }^{24}$

In a slightly different context, a study by Judith Rodin encouraged nursing home patients to contribute more to the policies determining their environment in the nursing home. Ninety three per cent became more alert, active and happy. ${ }^{25}$ Myers notes that 'similar results have been obtained after allowing prisoners to move chairs and control the room lights and the $\mathrm{TV}^{\prime}{ }^{26}$ Another interesting point to emerge is that the more developed the institutions of direct democracy, the happier the individuals are, irrespective of the outcome of the democratic process. ${ }^{27}$

\section{$2 \quad$ Pursing projects and goals}

People need to be active in pursuing projects. The more challenged a person is, whether by a job, hobby or sport, the happier he or she is likely to be. ${ }^{28}$ To this extent happiness results from intellectual and physical challenges, not mindless passivity - such as watching television. Studies have found that in general the less expensive (and generally more involving) a leisure activity, the happier people are doing it. Most people are happier gardening than power boating, talking to a friend than watching TV'. ${ }^{29} \mathrm{TV}$ in particular is inimical to happiness. The message here is clear - get off the couch and get active, do something! One proviso to this is that

\footnotetext{
${ }^{24}$ MYERS, supra $\mathrm{n} 1$, at 130.

${ }^{25}$ Judith Roden, Aging and Health: Effect of a Sense of Control, 233 SCIENCE 1271 (1986).

${ }^{26}$ MYERS, supra $\mathrm{n} 1$, at 115.

${ }^{27}$ D S Frey, Happiness Prospers in Democracy, 1 JOURnAl OF HAPPINESS STUDIES 79 (2000).

${ }^{28}$ The study was conducted by Professor M Argyle and is reported in Tom Reid, Some Research that May Bring You a Degree of Happiness, THE AGE, Oct. 61998.

${ }^{29}$ Myers, supra note 1 , at 137
} 
while work can be a source of satisfaction, it should not be over done. Regular periods of relaxation are conducive to happiness. ${ }^{30}$ In order for people to participate in activities and maintain a semblance of control in their lives it is important that people enjoy a large degree of personal autonomy and hence autonomy ranks highly on the happiness barometer.

\section{Happiness does not wildly fluctuate}

One of the other more interesting findings is that objective life circumstances have only a small part to play in one's sense of well being. Human beings are remarkably adaptable and resilient. ${ }^{31}$ The consistent (and astonishing) result is that people who experience the worst possible catastrophes (such as paralysis or being diagnosed with a life threatening illness) recover from these experiences to a point where their current mood is within a relatively short period of time more affected by the day's ordinary events than by the tragedy. ${ }^{32}$ The converse situation applies regarding dramatically positive events. For example, wining the lottery provides only a short term boost and in fact in the long run most lottery winners are less happy after winning the lottery than before the win. ${ }^{33}$ However, we are not slaves to our pasts and in-bred dispositions. Our traits and attitudes follow our behaviour. 'We are as likely to act ourselves into a new way of thinking as to think ourselves into a new way of acting'. ${ }^{34}$ In fact 'going through the motions [and telling yourself that you are happy] can trigger the emotion'. 35

\section{$4 \quad$ Age is irrelevant}

Happiness is not age dependent. While people think that adolescents and the elderly are the unhappiest, this is not true. People of all ages report similar feelings of wellbeing. ${ }^{36}$ In particular there is no evidence to support the supposed mid life crisis phenomena. Middle age people are no more dissatisfied than other people and there is no evidence of high levels of turmoil in this group of people. ${ }^{37}$ The only related finding was that as we get older our feelings mellow. Average happiness stays about the same, but as we age we are less often very excited or very sad, ${ }^{38}$ and as we age our priorities change. For example, older people report less satisfaction with their jobs and better align their aspirations with their attainments. ${ }^{39}$

\footnotetext{
${ }^{30}$ Id. at 139 .

${ }^{31}$ This stems from what is termed the emotional opponent- process principle. Emotions trigger opposite emotions - as with all psychological phenomena there are corresponding biological events: Id. at 54 . 


\section{$5 \quad$ Health and Gender as predictors of happiness}

Health and fitness is a particularly important predictor of happiness across all ages: 'more than a hundred studies confirm that for adults of all age ... one predictor of happiness is health and physical fitness'. ${ }^{40}$ Gender also has a role to play as a predictor of happiness. While men and women experience the same average happiness, women are twice as vulnerable to depression. ${ }^{41}$

\section{$6 \quad$ Self-esteem is good, but people overestimate their worth}

Studies also report a number of interesting traits that are relevant to happiness. One in particular is our tendency to hold self-serving biases. People accept more responsibility for good deeds than bad events, and for successes than for failures. ${ }^{42}$ On most subjective and socially desirable dimensions people see themselves as better than average. ${ }^{43}$ People have an inflated confidence in the accuracy of their beliefs and judgments and are quicker to believe flattering descriptions of themselves than unflattering ones. We also engage in group pride - believing our group is better than another group. ${ }^{44}$ However, this is not necessarily negative. Positive self illusions, which most of us have, protect us against anxiety and depression. Hence selfesteem is conducive to happiness.

\section{$7 \quad$ Close personal connections are important}

Close friendships are also important to health and happiness. ${ }^{45}$ Moreover, married people are normally happier than singles. ${ }^{46}$ More generally, individualist societies are less collectively happy than communal societies. It seems that the rights wave is an illusion: personal identity, which encourages people to pursue such behaviour as leaving home when opportunity strikes and not to compromise themselves, is selfdefeating. Being deprived of familiar attachments prompts a sense of meaninglessness:

People in competitive, individualist cultures such as the United States, have more independence, make more money, take more pride in personal achievements, are less geographically bound near elderly parents, are less likely to prejudge those outside their groups, and enjoy more privacy... But compared to collectivists, individualists are also lonlier, more alienated,

\footnotetext{
${ }^{40} I d$. at 76

${ }^{41} I d$. at 83 .

${ }^{42}$ Id. at 110 .

${ }^{43} I d$. at 111 .

${ }^{44} \mathrm{Id}$. at 111

${ }^{45}$ Id at, 144 .

${ }^{46}$ Id. at $\mathrm{Ch} 9$.
} 
less likely to feel romantic love, more likely to divorce, more homicidal, and more vulnerable to stress related diseases. ${ }^{47}$,

Ultimately, Myers notes that totalitarianism, materialism and self-reliant individualism have deluded us with false promises of well-being. ${ }^{48}$ In addition to this, there is a link between optimism and happiness. Optimists are healthier and enjoy greater success. ${ }^{49}$ Another trait of happy people is that they are more outgoing. Extroverts, in study after study, report greater happiness and satisfaction with life. ${ }^{50}$

\section{$8 \quad$ Money and Happiness}

One of the most interesting aspects of the research reported by Myers involved the association between money and happiness. Empirical studies consistently show that there is only a modest connection between wealth and happiness. Following what is probably the most extensive and expansive assessment of well-being ever conducted - with representative samples of 170,000 people in a number of different countries, Ronald Inglehart notes that there are significant national differences in the levels of happiness experienced by people. ${ }^{51}$ For example, year after year, the Danes, Irish and Dutch are happier and more satisfied with life than the French, Greeks and Italians. The results of this study showed that a nation's well-being correlated only modestly with national affluence. There seemed to be a far stronger connection between democracy and happiness. Interpreting these results David Myers states:

Moreover, the surveyed nations differ in ways other than affluence, making it hard to disentangle cause and effect. For one thing, the most prosperous nations have enjoyed stable democratic governments, and there is a striking link between a history of stable democracy and national wellbeing. The thirteen nations that have maintained democratic institutions continuously since 1920 all enjoy higher life satisfaction levels than do the nations whose democracies developed after World War II or have not yet fully emerged. ${ }^{52}$

Thus, across countries there is not a strong link between happiness and wealth. Similar results emerge within countries. It is not the case that within any country that the happiest people are the rich. ${ }^{53}$ This led Myers to conclude:

So, whether we base our conclusions on self-reported happiness, rates of depression, or teen problems, our becoming better off over the past thirty

\footnotetext{
${ }^{47} I d$. at $147-48$.

${ }^{48} I d$. at 207.

${ }^{49} \mathrm{Id}$. at 117 .

${ }^{50} \mathrm{Id}$. at 120 .

${ }^{51}$ RONALD INGLEHART, CUltURAL SHIFT IN ADVANCED INDUSTRIAL SOCIETY (1990).

${ }^{52}$ MYers, supra $\mathrm{n} 1$, at 36.

${ }^{53} I d$. at 39 .
} 
years has not been accompanied by one iota of increased happiness or life satisfaction ... Once beyond poverty, further economic growth does not appreciably improve [human happiness]. ${ }^{54}$

It seems that 'if not wracked by hunger or hurt, people at all income levels can enjoy one another and experience comparable joy'..$^{55}$ Another interesting finding is that happiness is relevant to the attainment of others: we feel good or bad depending on whom we compare ourselves to. ${ }^{56}$

Happiness shrivels with the gap between what we have and what we want, what we have and what we expected to have by now, what we have and what our neighbours have. ${ }^{57}$

This explains the reason that happiness increases when a person escapes poverty, but societies do not become happier as they progress from relative poverty to affluence. $^{58}$

A fundamental issue which emerges in the context of this paper is what is the point of diminishing returns beyond which more money no longer meaningfully contributes to our lives? In absolute terms the answer is the level of income that is necessary to provide one with the means necessary to provide for the essentials of living - food, shelter, and basic health care and education. Happiness also has a relative component. People who have less than their neighbours are unhappy about this. Thus, money ceases to have a significant effect on one's sense of well-being once they derive an average level of income.

This disassociation between wealth and happiness was confirmed in a study about a decade later by Tim Kasser. Tim Kasser's, The High Price of Materialism, published in $2002,{ }^{59}$ provides a useful scientific explanation as to why personal wellbeing is not connected to the accumulation of wealth, but rather depends on basic core needs - our indicators of happiness. The book provides a 'pyschological theory of materialism' and describes the research that supports it. This book is important due to the extensive research conducted by Kasser and his colleagues over a significant period of time. His research involved empirical studies, both clinical and laboratory that he and his colleagues conducted, as well as by other psychologists and social scientists, from countries around the globe. Importantly, the population samples included preschoolers, college students and adults from all around the world.

Kasser's study not only confirms previous studies in the area which have shown that beyond satisfying basic needs (such as food, shelter and clothing), further material

\footnotetext{
${ }_{55}^{54} I d$. at 43-44.

${ }^{55} I d$. at 39.

${ }^{56} I d$. , at 56

${ }^{57} \mathrm{Id}$. at 57.

${ }^{58} I d$. at 56

${ }^{59}$ Tim Kasser, The High Price OF MAterialism (2002).
} 
gain does little to improve our overall well-being, but shows that people who focus on the accumulation of wealth and material possessions are actually more likely to be unhappy, and will experience anxiety, depression, low self-esteem and other problems. Materialistic values, according to Kasser, are counter-productive as over time they heighten insecurity which is one of the primary causes of unhappiness.

Desires to have more and more material goods drive us into an ever more frantic pace of life. Not only must we work harder, but, once possessing the goods, we have to maintain, upgrade, replace, insure, and constantly manage them. Thus, in the journey of life, materialists end up carrying an everheavier load, one that expends the energy necessary for living, loving, and learning- the really satisfying aspects of that journey. Thus materialism, although promoting happiness, actually creates strain and stress. ${ }^{60}$

He further notes:

In recent years, scientific investigators working in a variety of fields have begun to tally the cost of a materialistic lifestyle. Although the body of empirical literature on materialism is not large, especially compared with what we know about topics such as depression, stereotyping, neurons, and memory, its findings are quite consistent. Indeed, what stands out across the studies is a simple fact: people who strongly value the pursuit of wealth and possessions report lower psychological well-being than those who are less concerned with such aims.

Kasser points out that a number of other investigators studying materialism have reached exactly the same conclusion as he did: that materialistic values are associated with low well-being. ${ }^{61}$ Kasser refers, for example, to an Australian study by Shaun Saunders and Don Munro that found that a materialistic outlook in Australian students was associated with increased feelings of anger, anxiety, and depression, along with decreased life satisfaction. Kasser goes on to state:

What happens to the quality of our lives when we value materialism? The answer, as we have seen from the studies described is, 'The more materialistic values are at the center of our lives, the more our quality of life is diminished'. In samples of adolescents, college students, and adults, with various means of measuring materialistic values and well-being, results show a clear pattern of psychological (and physical) difficulties associated with holding wealth, popularity, and image as relatively important. ${ }^{62}$

Perhaps the best illustration of this negative correlation between happiness and wealth creation comes from a study of lottery winners by Philip Brickman, which

\footnotetext{
${ }^{60} \mathrm{Id}$. at xi.

${ }^{61}$ Id. at 21 .

${ }^{62}$ Id. at 14
} 
Kasser refers to in his book. ${ }^{63}$ In this study, twenty-two individuals who had recently won large amounts of money in the Illonois state lottery were compared with a group of people who lived near the recently rich individuals. All study participants were asked about their general happiness and how much pleasure they derived from everyday experiences, such as talking with a friend, eating breakfast, hearing a funny joke, and the like. The happiness of lottery winners was no different from that of people who had not experienced a large increase in their wealth, and the lottery winners actually reported being less pleased with everyday events.

Kasser writes that materialism as a value can quickly lose its persuasiveness when it is shown that materialism is really a coping mechanism to respond to insecurity (caused by non-nurturing parents, anxiety, poverty etc), but which in the long-term leaves people feeling more insecure. According to Kasser:

My understanding of the connection among insecurity, a materialistic value orientation, and well-being is that sometimes people experience circumstances (non-nurturing parents, poverty, death anxiety) that lead them to feel insecure. This causes unhappiness and dissatisfaction, as security needs must be satisfied for good psychological health. At the same time, insecurity also makes it likely that people will pursue materialistic aims, as both inner predispositions and external consumer culture suggest that resources can purchase security. Thus, materialistic values are both a symptom of an underlying insecurity and a coping strategy taken on in an attempt to alleviate problems and satisfy needs. ${ }^{64}$

Happiness scientists also explain the quest for materialism as demonstrating our capacity for 'miswanting'. Daniel Gilbert of Harvard University's psychology department, working with a team including psychologist Tim Watson and Nobel laureate in economics, Daniel Kahneman, found from their study that our work in acquiring

[material] 'things'- such as homes, children, careers and wealth- is all based on how happy we predict they will make us. However, we overestimate the intensity of the happiness that these things bring, due to underestimating our capacity to adjust. For example, the new BMW will probably make us happy for a couple of weeks, or even months, but within about six months it will have become like wallpaper in our lives: there, but no longer able to provide the charge of joy it gave us initially. ${ }^{65}$

\section{$9 \quad$ Overview of happiness studies}

Thus in a nutshell the things that are conducive to happiness are fit and healthy bodies, realistic goals, self-esteem, optimism, an outgoing personality, a sense of

\footnotetext{
${ }^{63}$ Id. at 44

${ }^{64} \mathrm{Id}$. at 42.

${ }^{65}$ See J Macken, Hunt for Happiness, THE Australian Financial ReVIEW, Oct. 24, 2003.
} 
control, close relationships, challenging work and active leisure, punctuated by adequate rest and a faith that entails communal support, purpose and acceptance. Myths about happiness include that it is bought by money and that religious faith suppresses happiness.

Kasser forms similar conclusions to Myers regarding the things that are necessary for happiness. He states that there are four sets of 'psychological needs' that are necessary for the motivation, functioning and well-being of all humans: (1) safety, security and sustenance - the human desire to remain alive and avoid early death- ie roof over our heads, food on the table, clothing to protect us ("the essentials of life'); (2) competence, efficacy and self -esteem 'involves a feeling that we are capable of doing what we set out to do and of obtaining the things we value. Competence and esteem needs also entail a desire to have a more positive than negative view of ourselves and to like ourselves. In essence, to fulfil these needs each of us must feel like a competent and worthy person'; (3) connectedness- the human desire for intimacy and closeness with others - 'these needs lead us to belong to larger groups, such as churches, neighbourhood organizations, and teams. We need to feel that we belong and are connected with others' lives, be it as parents, friends, neighbours, or co-workers'; and (4) autonomy and authenticity- a desire for freedom to act on one's own and to have a feeling that one is self-directed, 'rather than feeling pressured or burdened by our circumstances, we need to pursue activities that provide us with challenge, interest and enjoyment. By doing so, we can feel ownership of our own behaviour, and thus feel both authentic and autonomous. ${ }^{166}$

According to Kasser, 'well-being and quality of life increase when these four sets of needs are satisfied and decrease when they are not. ${ }^{67}$ Kasser refers to these psychological needs as 'intrinsic' values, which are 'based in people's real psychological needs, support their growth and development, and are inherently satisfying to pursue'. Kasser states that:

Compared with materialistic people, those who believe intrinsic values are relatively important report greater happiness, enhanced psychological health, better interpersonal relationships, more personal contribution to the community, and more concern for ecological issues. These findings are substantiated by work of researchers using different value measures, and by research conducted with various age and cultural groups. ${ }^{6}$

\section{Positive psychology - types of happiness pleasures and gratifications}

The findings of Myers and Kasser are developed further by Martin Seligman who confers the label 'positive psychology' to the science of ascertaining the matters that

\footnotetext{
${ }^{66}$ KASSER, supra note 59, at 24-25. See K Ankomah, Book Review, 3 HuMAN NATURE REVIEW 108-109 (2003).

${ }^{67}$ KASSER, supra note 59, at 98 .

${ }^{68}$ Id. at 98
} 
are conducive to happiness. Positive psychology is a new movement (it only came on the scene at the end of the 1990's) concerned with the enhancement of happiness and well-being, and involves scientific studies into how the inherent personal strengths of individuals, along with positive social systems, can be utilised to achieve optimal happiness and well-being. This path of research is shifting psychologists' attention from a 'narrow minded focus' on human weaknesses (eg pathology, victimology, mental illness) towards our strengths (eg emotion and virtue), which can be nurtured through our daily activities and relationships. In this sense, in a new book (published in May 2004), Alan Carr refers to positive psychology as 'the science of happiness and human strengths'. ${ }^{69}$

Seligman in his book, Authentic Happiness, explains that his positive psychology consists of 'three pillars'.

First is the study of positive emotion. Second is the study of positive traits, foremost among them the strengths and virtues, but also the "abilities" such as intelligence and athleticism. Third is the study of the positive institutions, such as democracy, strong families, and free inquiry, that support the virtues, which in turn support the positive emotions. ${ }^{70}$

According to positive psychologists there is a very strong correlation between the level of effort that a person puts into an activity, and the level of pleasure and happiness that they experience from this activity. Seligman examines intensively the concept of happiness, and believes that it embraces two very 'distinct kinds of things': pleasures and gratifications.

'Pleasures' have very clear positive sensory and emotional components: ecstasy, thrills, orgasm, delight, mirth, exuberance, and comfort. They involve very little thinking, and thereby are essentially passive. In philosophy, these sensations are referred to as 'raw feels'. Gratifications, on the other hand, involve next to no 'raw feels', instead we become fully immersed and absorbed in the activity, through having to use our personal strengths to meet the challenge of fulfilling the action. Examples given by Seligman are rock climbing, reading a book, dancing and making a slam dunk. According to Seligman, the 'gratifications last longer than the pleasures, they involve quite a lot of thinking and interpretation, they do not habituate easily, and they are under-girdled by our strengths and virtues. ${ }^{.71}$ These findings are consistent with those of Myers which suggest that the pursuit of challenging

\footnotetext{
${ }^{69}$ See Alan Carr, Positive Psychology: The Science of Happiness and Human Strengths (2004), which looks at the possible applications of positive psychology in clinical practice. See also 41(1) JOURNAL OF HuMANisTiC PSYCHOLOGY (2001), a special issue on positive psychology, and M E P Seligman and M Csikszentmilhayi, Positive Psychology: An Introduction, 55 AMERICAN PSYCHOLOGIST 5-14 (2000). For a useful collection of commentaries on the application of positive psychology (and in particular the historical and contemporary research on human strengths), see also LISA ASPINWALL \&

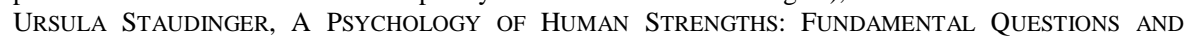
FUTURE DIRECTIONS FOR A POSITIVE PSYCHOLOGY 2003).

${ }^{70}$ Martin Seligman, AuthentiC HAPPINESS 102 (2002).

${ }^{71}$ Id. at xiii.
} 
endeavours (typically and characteristically, long term projects) is conducive to happiness.

Seligman goes on to explore the distinction between gratifications (long term pleasures) and pleasures (short term `treats'):

[Gratification] is part and parcel of right action. It cannot be derived from bodily pleasure, nor is it a state that can be chemically induced or attained by any shortcuts. It can only be had by activity consonant with noble purpose. ... The pleasures can be discovered, nurtured, and amplified ... but the gratifications cannot. The pleasures are about the senses and the emotions. The gratifications, in contrast, are about enacting personal strengths and weaknesses. ${ }^{7273}$

Based on this dichotomy, Seligman outlines the agenda and role of positive psychology:

The right question is the one Aristotle posed two thousand five hundred years ago: "What is the good life?" My main purpose in marking the gratifications off from the pleasures is to ask this great question anew, then provide a fresh and scientifically grounded answer. My answer is tied up in the identification and the use of your signature strengths. ${ }^{74}$

Importantly, to highlight the practical difference between gratifications and pleasures in terms of which is conducive to real happiness, Seligman refers to a study by Mike Csikzentmihalyi involving the experience sampling method (ESM). ${ }^{75}$ ESM involves given pagers to those being surveyed, which beep during different times of the day and night. Each time the pager beeped, participants were asked to record what they were doing at that moment- what they were thinking, what emotions they were feeling, and how engaged they were. The overall finding was that participants recorded a much higher level of psychological well-being (including self-esteem and engagement) from participating in active events, and mild depression when involved in more passive pursuits, such as watching television.

In Authentic Happiness, Seligman also considers the rise of depression in the United States and suggests that, contrary to other explanations for this development over the last few decades, the main reason for this depression is an increase in the amount of passive, as opposed to active, consumption by Americans and greater reliance on 'short term pleasures':

\footnotetext{
${ }^{72} I d$. at 112 .

${ }^{73}$ The distinction between gratifications and pleasures seems to correlate with the distinction that JS Mill made between 'lower pleasures', and 'higher pleasures' - the pleasures of the intellect, of the feelings and imagination, and of the moral sentiments: See the entry 'Happiness' in THE OXFORD COMPANION TO PHILOSOPHY 332 (1995).

${ }^{74}$ Seligman, supra note 70 , at 121 .

${ }^{75} \mathrm{Id}$. at 117.
} 
Depression is now ten times as prevalent as it was in 1960, and it strikes at a much younger age. ... This is a paradox, since every objective indicator of well-being- purchasing power, amount of education, availability of music, and nutrition- has been going north, while every indicator of subjective wellbeing has been going south. How is this epidemic to be explained?...

I have theorized that an ethos that builds unwarranted self-esteem, espouses victimology, and encourages rampant individualism has contributed to the subject ... [however] there is another factor that looms as a cause of the epidemic: the over-reliance on short-cuts to happiness. Every wealthy nation creates more and more shortcuts to pleasure: television, drugs, shopping, loveless sex, spectator sports, and chocolate to name but a few. ...

What would happen if my entire life were made up of such easy pleasures, never calling on my strengths, never presenting challenges? Such a life sets one up for depression. The strengths and virtues may wither during a life of taking shortcuts rather than choosing a life made full through the pursuit of gratifications. $^{76}$

When we engage in pleasures, we are perhaps just consuming. The smell of perfume, the taste of raspberries, and the sensuality of a scalp rub are all high momentary delights, but they do not build anything for the future. ...Pleasure marks the achievement of biological satiation, whereas gratification marks the achievement of psychological growth. ${ }^{77}$

\section{Doing, Not Having, is the Key}

It is important to note, however, that Van Boven and Gilovich make clear in their article that they are not suggesting that material purchases are simply not capable of making people happy. They make clear that 'the careful and measured acquisition of materials can no doubt advance one's happiness'. ${ }^{78}$ They go on: 'Our findings suggest, simply, that a person would be happier by investing in life experiences more than material possessions.' More generally, this study adds to the growing body of evidence suggesting that we are remarkably similar in the terms of the things that make us happy.

\section{Scientific Measurement of Happiness}

The view that happiness can be objectively verified is supported by recent developments in brain research. A recent article published in the New York Times, 'Finding Happiness: Cajole Your Brain to Lean to the Left', ${ }^{79}$ notes the work of brain

\footnotetext{
${ }^{76} \mathrm{Id}$. at 118 .

${ }_{77}^{7 d}$. at 116-17.

${ }^{78}$ Id. at 120-1.

${ }^{79}$ Daniel Coleman, Finding Happiness: Cajole Your Brain to Lean to the Left, NEw York Times, Feb 4, 2003.
} 
researcher Dr Richard Davidson, director of the Laboratory for Affective Neuroscience at the University of Wisconsin, who in recent research using functional M.R.I. and advanced EEG analysis, has identified an index for the brain's set point for moods.

The images show that when people are emotionally distressed (anxious, angry or depressed), the most active sites in the brain are circuitry converging on the amygdala (part of the brain's emotional centres) and the right prefrontal cortex. When people are in positive moods those sites are quiet and there is heightened activity in the left prefrontal cortex.

Davidson believes a ready way to ascertain a person's typical mood range is to read the baseline levels of activity in these right and left prefrontal areas. That ratio predicts daily moods with surprising accuracy. The more the ratio tilts to the left the more happy a person actually is.

By taking readings on hundreds of people, Davidson has established a bell curve distribution, with most people in the middle, having a mix of good and bad moods. The data suggests that biology has a strong influence on the set point for our emotional range. One finding, for instance (which confirms earlier work by Kasser noted above), is that 'both for people lucky enough to win a lottery and those unlucky souls who become paraplegic from an accident, by a year or so after the events their daily moods are about the same as before the momentous occurrences'. However, one's happiness set point is not beyond change, we are not slaves to our genes.

Davidson tested the left-right ratio on a senior Tibetan lama and he turned out to have the most extreme value to the left of the 175 people measured to that point. Moreover, happiness training is promising. A study by Davidson and Dr Jon KabatZinn, founder of the Mindfulness-Based Stress Reduction Clinic at the University of Massachusetts Medical School in Worcester, reports the effects of training in mindfulness meditation. Mindfulness was taught to workers in a high-pressure biotech business for approximately two months. After the training, on average, the workers ratio shifted leftward and reported feeling more energized and less anxious. Thus, the results suggest that the emotion set point can shift, given the proper training. ${ }^{80}$

\footnotetext{
${ }^{80}$ Another benefit for the workers, Davidson reported, was that mindfulness seemed to improve the robustness of their immune systems, as gauged by the amount of flu antibodies in their blood after receiving a flu shot. This supports the observations noted above concerning the link between happiness and physical health.
} 
The results of the above studies ${ }^{81}$ confirm the objective reality of happiness and its potential to guide law reform. We now discuss practical law reform implications that stem from the above discussion.

\section{RAMIFICATIONS FOR LEGAL DEVELOPMENT}

It takes little imagination to appreciate that the above discussion has considerable implications for the development of the law. Indeed there is virtually no area of the law that is not potentially affected by the above results and suggestions. It is beyond the scope of this paper (and indeed any paper) to catalogue the full range of reform measures that should be implemented to give effect to the happiness findings. However, on the basis of the evidence to date, by way of illustration, we provide some examples of the practical relevance of the findings for the law.

Prior to doing so we provide some comments regarding the manner in which happiness studies should be incorporated into the law reform agenda going forward. As a general rule, the starting point is that laws should only be passed if there is evidence to support the view that they are likely to promote happiness. In this regard we note that happiness research and science is still at a very early stage. There is still much to be learnt about the precise conditions that are most conducive to human happiness. Research in this area should be vigorously pursed. Once more results are

\footnotetext{
${ }^{81}$ Another measure of happiness may be facial expressions. However, this work is still in its early stages. In the same article by Coleman, supra note 79, it is noted that 'Dr. Ekman has developed a measure of how well a person can read another's moods as telegraphed in rapid, slight changes in facial muscles. ... These microexpressions ultrarapid facial actions, some lasting as little as one-twentieth of a second lay bare our most naked feelings. We are not aware we are making them; they cross our faces spontaneously and involuntarily, and so reveal for those who can read them our emotion of the moment, utterly uncensored. Perhaps luckily, there is a catch: almost no one can read these moments.... Dr. Ekman ... explains how people can learn to detect these expressions in just hours with proper training, [however] his testing shows that most people including judges, the police and psychotherapists are ordinarily no better at reading microexpressions than someone making random guesses. Yet when Dr. Ekman brought into the laboratory two Tibetan practitioners, one scored perfectly on reading three of six emotions tested for, and the other scored perfectly on four. And an American teacher of Buddhist meditation got a perfect score on all six, considered quite rare. Normally, a random guess will produce one correct answer in six. Such findings, along with urgings from the Dalai Lama, inspired Dr. Ekman to design a program called "Cultivating Emotional Balance," which combines methods extracted from Buddhism, like mindfulness, with synergistic training from modern psychology, like reading microexpressions, and seeks to help people better manage their emotions and relationships'.
} 
available, law makers will be well placed to know the social conditions that should be established to promote human flourishing.

Even at this relatively early point, however, we still know a considerable degree about the circumstances in which people flourish most. As noted above, things that are important to happiness include liberty (because it allows people to pursue their individual goals), a sense of participation and control in the activities that one engages in, close personal relationships, good health and the pursuit of challenging projects and activities. Things that do not make us happy are money (once we are beyond average income) and passive forms of conduct.

\section{A Attach much weight to liberty}

Given that liberty is conducive to happiness, it follows that laws which curtail liberty are only justifiable if they will compel or guide people to engage in conduct that empirical evidence demonstrably suggests will promote happiness, or if the laws will compel people to desist from conduct which it is proven will harm them. At the most general level, this means that restrictive laws which do not directly harm others should be repealed unless there is evidence to suggest that the proscribed conduct is detrimental to one's happiness. By way of example, planning laws restricting what one can do with his or her property and legal regulation of pornography should be relaxed. Moreover, legal regulation should be introduced discouraging people from engaging in passive pastimes. Thus, television coverage should be limited to, say, no more than four hours per day or, at the minimum, TV stations should be compelled to provide mental health warnings to their audience. Further, tax incentives should be given to organisations which provide facilities for people to pursue long term activities. In this way the government will encourage the establishment of more clubs where people play tennis or bridge, recite poetry, make pottery, play the violin and make wine.

\section{B Three concrete applications - Tax, Sentencing, Corpo- rate Governance}

On a more specific level, and by way of further example, we have suggested in a number of recent articles that developments in happiness research have significant implications for the revenue side of tax law, sentencing law and corporate governance.

In relation to laws levying taxation, we have noted that in terms of the effect of money on happiness (and hence the capacity to contribute to government revenue), there are three categories of people: those who do not have enough money, those who do have enough and those who have more than enough. There is obviously scope for considerable debate concerning exactly the rate at which tax should be levied for each of these categories. However, the following general observations can be made. People who do not earn enough money for the bare essentials are in a position where they are adversely affected by being required to divest any income 
through the taxation system. Thus, they should be taxed very lightly, if at all. People on roughly average incomes can afford to live with a little less, although every dollar less they have has a demonstrable connection with their level of happiness. Therefore they too should be taxed lightly. People on incomes above this can afford to pay a lot more tax and although they might not know it they will not experience any meaningful diminution in well-being if they have less money. They should be taxed heavily. We have suggested that this translates to the following rates of taxation. For income under approximately $\$ \mathrm{US} 15,000$ the rate should be 0 to 5 per cent. For income between \$US15,000 to \$US40,0000 (\$US40,000 still being above the average level of income in most, if not all, OCED countries) the rate should be about 10 - 15 per cent. Incomes beyond this level should be taxed at approximately 75 per cent. ${ }^{82}$

The main principle of sentencing law is the principle of proportionality which prescribes that the punishment should equal the crime. Despite its widespread acceptance, the principle offers no useful guide to sentencers, and penalty levels fluctuate greatly between jurisdictions and within jurisdictions. This is because there is no universally agreed criterion for measuring offence seriousness or penalty severity. We have suggested that the appropriate criterion for matching offence seriousness and penalty severity is the level of unhappiness or pain stemming from each of these impositions. This means, for example, the level of pain meted out to a rape offender should equal the level of pain caused to a rape victim. The pain/happiness criterion of offence seriousness and penalty severity will allow us to accurately match offence seriousness and penalty level. In order for this to occur a considerable amount of research would need to be undertaken concerning the actual impact that the different forms of criminal conduct and penalties have on wellbeing. Thus, surveys would need to be undertaken with statistically relevant numbers of (i) rape, assault, theft (etc...) victims; and (ii) offenders who (collectively) have been subjected to a cross-section of criminal sanctions, such as imprisonment (for various terms), fines and bonds, and the like. These surveys would assess the level of overall well-being of these people compared to that of people not afflicted by such experiences. The surveys would need to be undertaken at various time intervals to ascertain the full impact of such experiences. ${ }^{83}$ In light of the discussion in section three in this paper, it is likely that research of this nature will produce definitive results which can then be used to ensure that the punishment matches the crime.

As far as corporate governance is concerned, one of us has suggested that shareholding should be altered from what is essentially a passive role in the corporation (with the greatest 'experience' of shareholders being the receipt of dividend cheques and the potential to attend a general meeting once a year) to a far more active form of endeavour. This can only be made possible by fundamentally alter-

\footnotetext{
${ }^{82}$ This proposal is discussed at length in Mirko Bagaric \& James McConvill, Stop Taking Happiness, PITTSBURGH TAX REVIEW (2005, forthcoming).

${ }^{83}$ For further discussion, see Mirko Bagaric \& James McConvill, Giving Content to the Principle of Proportionality: Happiness and Pain as the Universal Currency for Matching Offence Seriousness and Penalty Severity, 69 JOURNAL OF CRIMINAL LAW 50.
} 
ing corporate governance structures that distance shareholders, the owners of the company, from the day-to-day affairs of the company due to the embedded assumption in corporate law that the best interests of shareholders equate with maximising profits rather than facilitating participation. This 'separation of ownership and control $^{84}$ should be bridged to make it possible for shareholders to have a greater input into the activities of corporations. ${ }^{85}$

Readers will no doubt question the soundness of some of these proposals. We emphasise, however, that we have made no attempt to provide a detailed justification for them. The recommendations are for illustrative purposes at this juncture elaborate justifications have been provided elsewhere. ${ }^{86}$ The point we are making is that the results of happiness studies have wide-ranging and pointed implications for legal regulation. It is imperative that law-makers become cognisant with this emerging body of knowledge and make it cardinal to the manner in which they develop the law. There is no reason why law-makers cannot engage in scientific inquiries, similar to what psychologists and economists have already done for their disciplines (and possibly with the help of these professionals), to get a more reliable sense of what will really be effective in making the law reflect and accommodate deep, underlying human instincts and objectives.

\section{A SUPERVISORY ROLE REMAINS FOR MORALITY}

Irrespective of which moral theory one subscribes to, we accept that if laws are developed with the aim of enhancing human happiness, there will be still some scope for the application of normative principles. A counter argument to our proposal will no doubt be that even if it is accepted that law-makers should seek to maximise happiness, it does not follow that they should do so in a way that will make each individual equally happy (or approximately so). A law which makes 90 per cent of the community very happy by making slaves of the other 10 per cent might generate more total happiness, than a law which makes every member of the community moderately happy.

In our view, as a sociological consideration, laws which directly violate important interests of one person to facilitate the happiness of others are unlikely to be effective tools for maximising happiness. The efficacy of a legal system is contingent on widespread community support. People seem to have a strong tendency to act on the basis of reciprocity. People who have their interests disregarded or undervalued are less likely to observe the interests of others. ${ }^{87}$ If the happiness of certain indi-

\footnotetext{
${ }^{84}$ See generally AdOLPH Berle \& GARdiner MeAns, The Modern Corporation ANd PRIVATE PROPERTY (1932, $2^{\text {nd }}$ ed, 1967).

${ }^{85}$ See James McConvill, The Separation of Ownership and Control under a Happiness Based of the Corporation, 26 THE COMPANY LAWYER 35 (2005).

${ }^{86}$ See supra notes 83,84 and 85.

${ }^{87}$ Evidence of this is the grossly disproportionate number of people from deprived social backgrounds in prison. For a discussion about the role of reciprocity, see R L Trivers, The Evolution of Reciprocal
} 
viduals or a group is demonstrably put above the rest of the community, history shows that considerable social upheaval will ultimately result, imperilling the security of many members of the community. In terms of effective legal regulation, we may win the battle in the short-term, but in the end literally lose the war. Thus, pragmatism alone would militate against the development of all laws which sacrificed small numbers of people for the well-being of the whole.

If, however, practical considerations are not sufficient to prevent such an approach we suggest that, in our model for legal development, moral norms should have a trumping role so as to prevent laws which sacrifice the interest of one for the good of another or others. This is a small but, potentially, not unimportant extension to our methodology. 88

\section{CONCLUSION}

We have suggested a new framework for developing and evaluating the law. The cardinal determinant is the extent to which the legal rule promotes happiness. We know that liberty is conducive to happiness. It follows that laws which curtail liberty should only be justifiable if there is evidence that shows that the encroachment will promote happiness more than suppress it. This approach ought to be adopted unless it is established that either (i) there is a more important human goal than happiness; or (ii) human beings are so diverse that it is not feasible to make valid generalisations concerning the matters that make people happy. This paper has been principally about repudiating attempts to make a sound argument in relation to the second form of rebuttal. Our argument against the first premise is so selfevident that we are confident that opponents will have little success in debunking this view. 'Better to be X (ie, rich, popular, dignified and so on) than happy' is not a statement that we believe will resonate strongly with many people.

Altruism, 46 QUARTERLy REVIEW OF BIOLOGY 35 (1971); ROBERT AXELROD, THE EVOLUTION OF COOPERATION (1984).

${ }^{88}$ We note that such a qualification (that one person should not be sacrificed for another) stems from either a consequentialist or rights-based normative ethic: see Bagaric, supra note 9. 